\title{
JOURNAL OF EXPERIMENTAL BIOLOGY
}

\section{Derived loss of signal complexity and plasticity in a genus of weakly electric fish}

\author{
David E. Saenz ${ }^{1}$, Tingting Gu², Yue Ban³, Kirk O. Winemiller¹, Michael R. Markham ${ }^{4,5}$ \\ ${ }^{1}$ Department of Ecology and Conservation Biology, Texas A\&M University, College Station, TX, 77843, \\ USA. \\ ${ }^{2}$ Sam Noble Microscopy Laboratory, University of Oklahoma, Norman, OK, 73019, USA \\ ${ }^{3}$ Neurobiology section, Biological Sciences Division, University of California, San Diego, La Jolla, CA, \\ 92093 \\ ${ }^{4}$ Department of Biology, University of Oklahoma, Norman, OK, 73019, USA \\ ${ }^{5}$ Cellular \& Behavioral Neurobiology Graduate Program, University of Oklahoma, Norman, OK \\ 73019, USA
}

Running title: Derived loss of signal complexity

Key words: Electric fish, signal plasticity, melanocortin hormones, adrenocorticotropic hormone

\author{
Corresponding Author: \\ Michael R. Markham \\ Department of Biology \\ University of Oklahoma \\ 730 Van Vleet Oval, RH410 \\ Norman, OK 73019
}

Email: markham@ou.edu

Phone: 1-405-325-6760 


\begin{abstract}
Signal plasticity can maximize the usefulness of costly animal signals such as the electric organ discharges (EODs) of weakly electric fishes. Some species of the order Gymnotiformes rapidly alter their EOD amplitude and duration in response to circadian cues and social stimuli. How this plasticity is maintained across related species with different degrees of signal complexity is poorly understood. In one genus of weakly electric gymnotiform fish (Brachyhypopomus) only one species, B. bennetti, produces a monophasic signal while all other species emit complex biphasic or multiphasic EOD waveforms produced by two overlapping but asynchronous action potentials in each electric organ cell (electrocyte). One consequence of this signal complexity is the suppression of low-frequency signal content that is detectable by electroreceptive predators. In complex EODs, reduction of the EOD amplitude and duration during daytime inactivity can decrease both predation risk and the metabolic cost of EOD generation. We compared EOD plasticity and its underlying physiology in Brachyhypopomus focusing on B. bennetti. We found that $B$. bennetti exhibits minimal EOD plasticity, but that its electrocytes retained vestigial mechanisms of biphasic signaling and vestigial mechanisms for modulating the EOD amplitude. These results suggest that this species represents a transitional phenotypic state within a clade where signal complexity and plasticity were initially gained and then lost. We discuss potential the roles of signal mimicry, species recognition, and sexual selection in maintaining the monophasic EOD phenotype in the face of detection by electroreceptive predators.
\end{abstract}




\section{Introduction}

Signal plasticity is one means for organisms to overcome trade-offs associated with costly communication signals. This is especially true for multi-functional signals such as echolocation calls or the electric organ discharges (EODs) of weakly electric fishes. Few studies have examined the evolution and maintenance of signal plasticity in a phylogenetic context. Here we compare signal plasticity in a genus of weakly electric fish and report a case in which a loss of signal complexity is associated with a strong reduction in signal plasticity, likely at great metabolic cost.

Gymnotiform fishes emit and detect weak electric fields to communicate with conspecifics and navigate in dark waters. The EOD is produced by the near-simultaneous action potentials of excitable cells (electrocytes) in the electric organ. Across their phylogeny, gymnotiforms have evolved diverse signals that vary in parameters such as discharge rate and waveform (Albert \& Crampton 2005). The impressive diversity of EOD waveforms is due in part to differences in electrocyte morphology as well as the diversity, kinetics, and spatial distribution of the ion channels in these excitable cells (Markham 2013; Markham \& Stoddard 2013).

Despite its high species diversity and wide geographical range, the genus Brachyhypopomus (Hypopomidae) is well studied relative to other gymnotiforms, especially its phylogeny (Fig. 1) (Crampton et al. 2016a,b) and its ecology (Waddell et al. 2019), making these fishes particularly useful for comparative evolution and neurophysiology research.

Of the 28 Brachyhypopomus species described, the EODs of 18 species are known, 12 of which are biphasic, 5 are multiphasic, and 1 is monophasic (Fig. 1; Sullivan et al. 2013). Monophasy is a rare characteristic among weakly electric fishes, presumably because of its potential detection by electroreceptive predators (Stoddard 1999; Stoddard \& Markham 2008). Of the larval Brachyhypopomus species recorded, all of them begin generating monophasic EODs and transition to more complex waveforms as they mature (Franchina 1997; Crampton et al. 2016b). This is thought to be the case for all gymnotiform fishes and the monophasic EOD is generally considered to be the ancestral trait (Stoddard 2002), though this has not been confirmed due to phylogenetic uncertainties between the families (Arnegard et al. 2010; Lovejoy et al. 2010; Tagliacollo et al. 2016; Alda et al. 2018).

In some gymnotiforms, crucial signal parameters such as phase, amplitude, duration, and low-frequency content vary by sex and ontogeny, and are regulated in response to seasonal, 
circadian, and social cues (Silva et al. 2002; Silva et al. 2007; Markham et al. 2009). This signal plasticity is regulated by steroid and peptide hormones, with peptide hormones playing a major role in regulating short-term circadian and social changes (Allee et al. 2009). Here we show how one form of short-term signaling plasticity that is regulated by melanocortin hormones varies between closely related species of Brachyhypopomus.

The general physiology of EOD is reviewed by Markham (2013; See Fig.1 therein) but, briefly, biphasic Brachyhypopomus electrocytes are large disc-shaped cells innervated on the posterior side (Bennett 1961, 1971; Trujillo-Cenoz et al. 1984). The biphasic EOD is the result of two action potentials (APs). The first AP (AP1) occurs at the posterior face of the electrocytes in the direction of the head and the second (AP2) occurs at the anterior face in the direction of the tail. The summation of the APs in a single electrocyte produces a biphasic single-cell discharge $(\mu \mathrm{EOD})$ and the whole EOD is a sum of the composite $\mu$ EODs

Previous work has shown that some gymnotiform species increase EOD amplitude (EODa) in response to circadian and social cues (Fig. 1), and that this amplitude plasticity is regulated by melanocortin hormones, such as adrenocorticotropic hormone (ACTH) (Markham \& Stoddard 2005). Increasing EODa during nocturnal activity increases the metabolic cost as well as the active space of the signal, which carries implications for prey detection and for signal detection by both conspecifics and electroreceptive predators (Salazar \& Stoddard 2008; Stoddard \& Markham 2008; Stoddard et al. 2019). In B. gauderio, EODa is thought to be important for dominance displays and mate choice (Curtis \& Stoddard 2003; Gavassa et al., 2012b).

All Brachyhypopomus species studied to date show pronounced modulations of EODa. To better understand the function and physiology of EODa plasticity, we compared the effects of ACTH in three additional species of Brachyhypopomus, and focused on one species in particular, B. bennetti, the only congener that emits a monophasic EOD. We expected that $B$. bennetti would show EODa plasticity on the same scale as other Brachyhypopomus species due to its relatively large EODa (Crampton \& Albert 2006) and the potential conspicuousness of its monophasic EOD to electroreceptive predators (Stoddard 1999; Stoddard \& Markham 2008). Additionally, we hypothesized that reversion to a monophasic EOD occurred in B. bennetti by the loss of voltage-gated $\mathrm{Na}^{+}$channels and electrical excitability on the anterior face, matching the general organization of electrocytes in another gymnotiform with a monophasic EOD, the 
Electric Eel (Electrophorus electricus) (Ellisman \& Levinson 1982; Fritz et al. 1983). We found that $B$. bennetti exhibited only minor EODa plasticity and, more surprisingly, that the anterior membrane of $B$. bennetti electrocytes expresses voltage-gated $\mathrm{Na}^{+}$channels and is electrically active.

\section{Materials and Methods}

\section{Animals}

A major limitation to working with this system is that it can be exceedingly difficult to reliably and responsibly acquire specific species. At this time, $B$. gauderio is the only species of Brachyhypopomus dependably bred in captivity. Individuals of $B$. bennetti and B. brevirostris were wild caught from Manaus, Brazil and exported in collaboration with researchers at the Brazilian Institute of Amazonian Research under ICMBio authorizations \#14833 and \#14834. These fish can be highly sensitive to the stressors of transport so ultimately we had only a total of 8 individuals of $B$. bennetti and 1 B. brevirostris for in vitro experiments. Specimens of $B$. gauderio were captive-bred from colonies maintained at the University of Oklahoma. All methods were approved in advance by the Institutional Animal Care and Use Committees of Texas A\&M University and the University of Oklahoma.

\section{Immunohistochemistry}

We immunolabeled voltage-gated $\mathrm{Na}^{+}$channels and axon terminals in the electric organ using antibodies and protocols described previously (Ban et al., 2015). We labeled voltage-gated $\mathrm{Na}^{+}$ channels with an Anti-Pan $\mathrm{Na}_{\mathrm{v}}$ antibody (Alomone Labs, Jerusalem, Israel) that has been validated in electric fish (Ban, et al., 2015), and we labeled axon terminals with 3A10 (developed by T. Jessel and J. Dodd, and obtained from DSHB). For B. bennetti tissue ( $\mathrm{n}=2$ fish), selected sections were imaged on a Leica SP8 confocal laser scanning microscope using a 20x 0.75 NA oil objective. A GaN 405 laser with a $405 \mathrm{~nm}$ laser line was used to excite DAPI with an emission detection window between $415 \mathrm{~nm}$ and $455 \mathrm{~nm}$. Similarly, an Argon laser line was used to excite the Alexa Fluor 488 and an emission detection window was set at $550 \mathrm{~nm}$ to 5500 nm. Z-series of images were acquired via sequential scanning. For B. gauderio tissues, immunolabeled sections were imaged on a Zeiss ApoTome. 2 microscope with 5x/0.16NA, 10x/0.45NA, and 20x/0.80NA dry objectives. Images were acquired using a Zeiss AxioCam MRm and then processed by Zeiss AxioVision Rel.4.8. We created optical sections of the 
fluorescent samples using structured illumination. Image contrast was adjusted in Fiji and Adobe Photoshop for better visualization of fine structures in the electrocytes.

\section{Injections and recordings}

EODs were recorded using a pair of silver electrodes on either side of the fish. EODs were amplified using a BMA 200 AC/DC Bioamplifier (CWE, Inc., USA) and digitized at 16 bits resolution using an A/D converter (CE Data translation USB Data Acquisition, USA) at a sampling rate of at least $50 \mathrm{kHz}$. Baseline EOD recordings were made for a minimum of 30 minutes. Fish were then quickly removed from the tank and given an intramuscular injection $(1 \mu \mathrm{l} / \mathrm{g})$ of either $30 \mu \mathrm{M}$ ACTH or normal saline in a process that took less than 15 seconds.

\section{Circadian recordings}

Circadian recordings were conducted using an automated system for recording calibrated EODs round-the-clock from freely swimming fish described previously Stoddard et al. (2003). EODs were recorded at $\sim 60$-second intervals for at least three days to assess circadian variation in EOD waveform.

\section{Solutions for in vivo injections and in vitro electrophysiology}

The normal saline contained $114 \mathrm{NaCl}, 2 \mathrm{KCl}, 4 \mathrm{CaCl}_{2} \cdot 2 \mathrm{H}_{2} \mathrm{O}, 2 \mathrm{MgCl}_{2} \cdot 6 \mathrm{H} 20,5 \mathrm{HEPES}, 6$ glucose; $\mathrm{pH}$ to 7.2 with $\mathrm{NaOH}$. For some in vitro experiments with $B$. bennetti electrocytes, $\mathrm{NaCl}$ was substituted with choline chloride to reduce the $\mathrm{Na}^{+}$concentration to $14.5 \mathrm{mM}$, and pancuroium bromide $(1 \mu \mathrm{M})$ was added to the saline. Adrenocorticotropic hormone (ACTH from porcine pituitary) was purchased from Sigma Aldrich (St. Louis, MO)., Tetraethyl ammonium (TEA), barium chloride, and pancuronium bromide were obtained from Millipore-Sigma.

Collagenase (type IV, Worthington Biochemical, Lakewood, NJ) was prepared in normal saline.

\section{Electrophysiology}

To record discharges from single electrocytes ( $\mu$ EODs) we removed a small piece of the tail ( $1 \mathrm{~cm}$ ) and carefully dissected the skin off to expose electric organ. The tissue was pinned into a Sylgard-coated recording dish and incubated in saline with $2 \%$ collagenase for 45 minutes to weaken the tissue surrounding the electrocytes. The preparation was then flushed several times with normal saline at $\mathrm{RT}\left(23 \pm 1^{\circ} \mathrm{C}\right)$ over a period of at least 15 minutes before recording. 
Current clamp: Intracellular stimulation and recordings used an Axoclamp 900A amplifier (Molecular Devices, Union City, CA) and extracellular recordings were completed using a Dagan TEV200A amplifier (Dagan Corp, Minneapolis, MN) in current clamp mode. A Digidata 1440 interface and PClamp 10.0 software (Molecular Devices, San Jose, CA) were used to control all amplifiers. Data were sampled and digitized at $100 \mathrm{kHz}$ sampling rate. Extracellular pipettes were pulled from borosilicate glass and had resistances between 400-600 K $\Omega$ when filled with normal saline. Intracellular pipettes had resistances of 0.8-1.2 $\mathrm{M} \Omega$ when filled with $3 \mathrm{M} \mathrm{KCl}$.

We used a multi-electrode current clamp procedure to record APs from single electrocyte membranes in a procedure described in more detail elsewhere (Bennett 1961; Markham \& Stoddard 2005, Markham \& Zakon 2014). One intracellular pipette delivered a depolarizing current step to elicit the $\mu$ EOD. A second intracellular pipette recorded the intracellular potential and two extracellular pipettes placed within $50 \mu \mathrm{m}$ of the posterior and anterior membranes recorded extracellular potentials, one from each membrane. Off-line subtraction of the posterior extracellular record and the anterior extracellular record from the intracellular record result in AP1 and AP2 respectively. Subtraction of the posterior extracellular record from the anterior extracellular record returns the $\mu \mathrm{EOD}$.

Only electrocytes with stable resting potentials $<80 \mathrm{mV}$ and input resistances were recorded. Once all the electrodes were in place, we delivered 6-ms depolarizing current steps while manually adjusting the stimulus current magnitude until a $\mu$ EOD was dependably elicited. A baseline recording was made of $\mu$ EODs every 60 seconds for at least 15 minutes, after which we perfused normal saline for control cells or normal saline containing $100 \mathrm{nM}$ ACTH. Due to the limited number of specimens, the timing of ACTH application and the length of the baseline recordings were staggered between individuals as an added measure of control for nonspecific effects. Solutions were changed during the interstimulus interval with a quick perfusion of $5 \mathrm{~mL}$ followed by slow continuous perfusion at $5 \mathrm{~mL} / \mathrm{h}$. We recorded $\mu$ EODs at 60 second intervals for the remainder of the experiment.

Two-electrode voltage clamp: Holding potential for all cells was $-90 \mathrm{mV}$. Whole cell currents were recorded in normal saline in response to voltage steps from $140 \mathrm{mV}$ to $0 \mathrm{mV}$ in 5 $\mathrm{mV}$ increments. $\mathrm{Na}^{+}$currents $\left(\mathrm{I}_{\mathrm{Na}}\right)$ were recorded in reduced- $\mathrm{Na}^{+}$saline $(14.5 \mathrm{mM} \mathrm{NaCl})$ with 2 $\mathrm{mM} \mathrm{BaCl}^{2+}$ and $10 \mathrm{mM}$ TEA to block any $\mathrm{K}^{+}$conductances, and $1 \mu \mathrm{M}$ pancuronium bromide to 
prevent spontaneous contraction of tail muscles. Voltage clamp protocols to assess $\mathrm{Na}^{+}$ current $\left(\mathrm{I}_{\mathrm{Na}}\right)$ activation and inactivation consisted of a $50 \mathrm{~ms}$ conditioning step to -120 $\mathrm{mV}$ followed by $20 \mathrm{~ms}$ voltage steps from -120 to $25 \mathrm{mV}$ in $5 \mathrm{mV}$ increments and then a $20 \mathrm{~ms}$ step to $0 \mathrm{mV}$. Recovery of $\mathrm{I}_{\mathrm{Na}}$ from inactivation was assessed with a protocol that consisted of a $50 \mathrm{~ms}$ conditioning step to $-120 \mathrm{mV}$ followed by an activation step to 0 $\mathrm{mV}$ and a recovery step to $-120 \mathrm{mV}$ for $0.5 \mathrm{~ms}$ to $12.5 \mathrm{~ms}$ in $0.5 \mathrm{~ms}$ increments and then a step to a test potential of $0 \mathrm{mV}$ for $20 \mathrm{~ms}$.

\section{Data treatment and analysis}

For in vivo experiments, paired t-tests were used to compare percent changes in EOD parameters (relative to baseline) between in ACTH and saline. The same was done for the current clamp data. Statistical analyses were not performed for the injection data on B. cf. hamiltoni or for current clamp data on B. brevirostris because only one individual was available for each experiment (see results for modified procedure). Electrophysiology data were analyzed with Clampfit 10.7.0. (Molecular Devices) and Matlab (Mathworks, Natick, MA).

\section{Computational simulations}

For numerical simulations we modeled the electrocyte as three cylindrical compartments arranged as a passive central compartment coupled to two flanking active compartments. External stimulation current was applied only to the central compartment, consistent with experimental procedure. The capacitance $C_{C}$ for the central compartment was $100 \mathrm{nF}$ and the capacitances of the posterior and anterior compartments, $\mathrm{C}_{\mathrm{P}}$ and $\mathrm{C}_{\mathrm{A}}$ respectively, were $50 \mathrm{nF}$, yielding a total membrane capacitance of $150 \mathrm{nF}$ consistent with empirical measurements of whole-cell capacitance. Differential equations were coded and integrated with Matlab using Euler's method with integration time steps of $1 \times 10^{-9} \mathrm{sec}$. All model parameters are shown in Table 1.

The passive central compartment's current balance equation included only terms representing the injected stimulation current pulses $\mathrm{I}_{\text {Stim }}(t)$, passive leak $\left(\mathrm{I}_{\mathrm{LC}}\right)$, and coupling to the two active compartments: 


$$
C_{C} \frac{d V_{c}}{d t}=I_{S t i m}(t)-I_{L C}+g_{w}\left(V_{a}-V_{c}\right)+g_{w}\left(V_{p}-V_{c}\right)
$$

where $g_{w}$ is the coupling conductance, fixed at $7 \mu \mathrm{S}$ for all compartments, $s$ is the coupling ratio, fixed at $0.334, \mathrm{~V}$ is the membrane potential, and $\mathrm{I}_{\mathrm{LC}}$ is the passive leak current given by the equation

$$
I_{L C}=\bar{g}_{\mathrm{LC}}\left(\mathrm{V}_{C}+90\right)
$$

where $\bar{g}_{\mathrm{LC}}=5 \mu \mathrm{S}$.

The current balance equations for the anterior and posterior active compartments were, respectively:

$$
\begin{aligned}
& C_{A} \frac{\mathrm{dV_{ \textrm {a } }}}{\mathrm{dt}}=-\mathrm{I}_{\mathrm{NaA}}-\mathrm{I}_{\mathrm{LA}}+g_{w}\left(V_{C}-V_{A}\right) \\
& C_{P} \frac{\mathrm{dV}_{\mathrm{p}}}{\mathrm{dt}}=-\mathrm{I}_{\mathrm{NaP}}-\mathrm{I}_{\mathrm{LP}}+g_{w}\left(V_{C}-V_{P}\right)
\end{aligned}
$$

where $\mathrm{V}$ is the membrane potential, $\mathrm{I}_{\mathrm{Na}}$ represents $\mathrm{Na}^{+}$current, and $\mathrm{I}_{\mathrm{L}}$ is the leak current. Equations for these currents were as follows:

$$
\begin{aligned}
& I_{N a A}=\bar{g}_{N a A} m^{3} h\left(V_{A}-E_{N a}\right) \\
& I_{N a P}=\bar{g}_{N a P} m^{3} h\left(V_{P}-E_{N a}\right) \\
& I_{L A}=\bar{g}_{\mathrm{LA}}\left(\mathrm{V}_{A}+95\right) \\
& I_{L P}=\bar{g}_{\mathrm{LP}}\left(\mathrm{V}_{P}+95\right)
\end{aligned}
$$

The gating variables in Equations 5 and 6 are evolved by Equation 9 where $\mathrm{j}=\mathrm{m}$ or $\mathrm{h}$ :

$$
\frac{d j}{d t}=\frac{j_{\infty}\left(V_{m}\right)-j}{\tau_{j}\left(V_{m}\right)}
$$

The values of $j_{\infty}$ were determined in a voltage-dependent fashion as follows:

$$
j_{\infty}=\frac{1}{1+\exp \left(\frac{V 50_{j}-V_{m}}{k_{j}}\right)}
$$

where $V 50_{j}$ and $k_{j}$ are derived from Boltzmann sigmoidal fits to experimental data and are given in Table 1. $\tau_{j}$ is given by Eqn. 11 for $\mathrm{j}=\mathrm{m}$ : 


$$
\tau_{j}=\frac{\alpha_{j}}{1+\left(\frac{V_{m}-\mu_{j}}{\sigma_{j}}\right)^{2}}+\beta_{j}
$$

and by Eqn. 12 for $\mathrm{j}=\mathrm{h}$ :

$$
\tau_{j}=\alpha_{j} \times \exp \left(-0.5 \times\left(\frac{V_{m}-\mu_{j}}{\sigma_{j}}\right)^{2}\right)+\beta_{j}
$$

Where values of $\alpha_{j}, \beta_{j}, \mu_{j}$, and $\sigma_{j}$ were determined by least-squares best fits to our experimental voltage-clamp data and are given in Table 1.

\section{Results}

\section{Immunolocalization}

Immunohistochemistry confirmed that electrocytes are innervated on the posterior stalk by spinal electromotor neurons in B. bennetti and B. gauderio (Fig. 2G-L and Fig. 3D-E, respectively). As expected in B. gauderio, $\mathrm{Na}^{+}$channels were found on both the posterior and anterior membranes (Fig. 3A-C). Contrary to our expectations, $\mathrm{Na}^{+}$channels were also found on both the posterior and anterior membranes of B. bennetti (Fig. 2D-F and Fig. 4). Interestingly, $\mathrm{Na}^{+}$channels also appeared on internal cell structures (Fig. 3B, 4F). Due to limited availability of specimens, we were unable to quantify the $\mathrm{Na}^{+}$channels. $B$. bennetti electrocytes are large ( 600-900 $\mu \mathrm{m}$ in length) and the labeling of $\mathrm{Na}^{+}$channels varies depending on where the cells were sectioned.

\section{Effects of ACTH in vivo}

We found that intramuscular injections of ACTH significantly increased the peak-to-peak EODa in the biphasic species, B. brevirostris, and B. cf. hamiltoni $(33.7 \pm 4.7 \%$ and $16.1 \%$; $\mathrm{n}=6$ and 1, respectively), as has been shown for B. gauderio (Markham \& Stoddard, 2013). Separate evaluation of the phases in B. brevirostris showed that amplitude of both P1 and P2 increased $(\mathrm{t}=2.23, \mathrm{p}=0.056)$. On average, ACTH also increased EODa in B. bennetti, however, the effect was considerably weaker $(\mathrm{t}=2.45, \mathrm{p}=0.094 ; \mathrm{n}=6)$. Saline controls slightly decreased the EODa in all four species. The duration of both P1 and P2 (measured at 2\% of the peak amplitude) increased in B. brevirostris ( $\mathrm{p}<0.001, \mathrm{t}=2.57$ ) and B. cf. hamiltoni. In B. bennetti, the duration of the EOD did not change appreciably. 


\section{Effects of ACTH in vitro}

Using a multi-electrode current clamp, we measured $\mu$ EOD parameters from individual electrocytes of B. brevirostris and B. bennetti. As previous studies have shown in B. gauderio (Markham \& Stoddard 2005; Markham et al. 2009; Markham et al. 2013), ACTH increased amplitudes of both $\mathrm{P} 1$ and $\mathrm{P} 2$ of the $\mu \mathrm{EOD}$ in $B$. brevirostris, and concurrently, the total $\mu \mathrm{EOD}$ amplitude (Fig. 5C-D), the duration of P2, and the AP1-AP2 delay (data not shown). Because only one individual was available for testing, we attempted to wash out the ACTH after 30 minutes with saline (60 min of the total recording), during which we observed a slow decrease in $\mu$ EOD amplitude over the course of the next hour. We then reapplied ACTH and saw a small increase again in the $\mu$ EOD amplitude (Fig. 5D). In B. bennetti, ACTH also increased the amplitude of the $\mu$ EOD (Fig. 5A-B; n=4), however the effect was much smaller relative to $B$. gauderio and B. brevirostris. Again, contrary our expectations, we observed APs on both the posterior and the anterior membrane (Fig.5A). Perfusion of ACTH slightly increased both AP1 and AP2. No other parameters showed consistent changes in response to ACTH.

\section{Ionic currents in Brachyhypopomus bennetti electrocytes}

Whole-cell currents recorded in voltage clamp showed an extremely large transient inward current that could not be controlled by the amplifier even at its maximum gain $(50,000$ $\mathrm{V} / \mathrm{V})$. Currents at steady state could be controlled by the amplifier's steady-state gain $\left(10^{6} \mathrm{~V} / \mathrm{V}\right)$. Steady state I-V relationships were linear, showing no evidence of meaningful inward- or outward-rectifying $\mathrm{K}^{+}$conductances (Fig. 6A).

Given the apparent absence of significant voltage-gated $\mathrm{K}^{+}$currents and the paucity of subject animals, we focused on describing the $\mathrm{Na}^{+}$conductances in B. bennetti electrocytes because they are apparently the dominant ionic conductance shaping the electrocyte APs. We used a reduced- $\mathrm{Na}^{+}$extracellular saline solution $(14.5 \mathrm{mM} \mathrm{NaCl})$ to reduce the driving force on $\mathrm{I}_{\mathrm{Na}}$ and allow stable voltage clamp control during $\mathrm{I}_{\mathrm{Na}}$ activation. $B$. bennetti electrocytes showed transient inward $\mathrm{Na}^{+}$currents (Fig. 6B-C) with typical voltage dependence of activation and inactivation time constants (Figure 6D). The time constant of recovery from inactivation $(\tau=$ $3.80 \mathrm{~ms}$; Fig. 6E) is the slowest for any gymnotiform species thus far reported, by a factor of four (cf. Ferrari et al., 1995; Markham et al., 2013; Markham and Zakon, 2014). This is not completely unexpected considering $B$. bennetti has a very low EOD frequency $(<10 \mathrm{~Hz})$. 


\section{Computational electrocyte simulations}

With parameters derived from our voltage clamp data, we simulated B. bennetti electrocytes to evaluate whether our experimentally-observed $\mathrm{Na}^{+}$channel localizations, $\mathrm{Na}^{+}$ conductances, and electrocyte passive properties are sufficient and necessary to reproduce the electrocyte APs recorded in vitro, and to reproduce the effects of ACTH observed during our current clamp recordings. The model electrocyte, which included $\mathrm{Na}^{+}$conductances in both the posterior and anterior compartments, produced simulated AP1, AP2, and $\mu$ EOD waveforms (Fig. 7A) that were strikingly consistent with experimentally recorded waveforms (cf. Fig. 5A). Increasing the $\mathrm{Na}^{+}$conductance by $10 \%$ in both anterior and posterior compartments increased AP1, AP2, and $\mu$ EOD amplitude in the model cell (Fig. 7A) in a manner nearly identical to the effects of ACTH recorded in vitro (cf. Fig. 5A).

To test whether $\mathrm{Na}^{+}$conductances in the anterior compartment are necessary to reproduce our experimental results, we evaluated the performance of two alternate model electrocytes. In one model, we eliminated the anterior-compartment $\mathrm{Na}^{+}$conductance. This model failed to reproduce experimentally-recorded AP1, AP2, and $\mu \mathrm{EOD}$ waveforms, as well as the observed effects of ACTH (Fig. 7B), even across a broad range of posterior-compartment $\mathrm{Na}^{+}$ conductance densities (data not shown). In a second alternate model, we eliminated the anteriorcompartment $\mathrm{Na}^{+}$conductance, but increased the anterior-compartment capacitance up to tenfold in order to test an earlier proposal that AP2 is a result of capacitative discharge from the anterior membrane (Bennett, 1971). This model also failed to reproduce experimental findings (Fig. 7C) even across a broad range of anterior-compartment capacitances and posterior-compartment $\mathrm{Na}^{+}$ conductance densities (data not shown). Taken together with our experimental data, these simulations support the conclusion that both anterior and posterior compartments of B. bennetti electrocytes are electrically active, and endowed with voltage-gated $\mathrm{Na}^{+}$channels. 


\section{Discussion}

An obvious limitation of the experiments reported here is the limited sample size, a sometimes unavoidable consequence of collecting specimens in the wild. A further difficulty when working with specific species of gymnotiforms is that they are rarely, if ever, available through commercial fish importers because these fish can be tremendously difficult to identify at the species level without conducting detailed morphological analysis or EOD recordings. We compensated for restricted sample sizes wherever possible by using staggered baselines and other such strategies as described in the methods and results. Nonetheless, caution is called for with respect to the most striking observations here: that $B$. bennetti shows greatly reduced EOD plasticity compared to other Brachyhypopomid species and that both the anterior and posterior membranes of $B$. bennetti electrocytes are electrically active. In support of these conclusions, however, it is important to note that multiple approaches and sources of evidence (in vivo recordings, in vitro electrophysiology, immunolabeling, and computational simulations) all converged on the same outcomes.

\section{EOD plasticity in Brachyhypopomus}

Relative to the other congeners studied, B. bennetti exhibited minimal EOD plasticity. Previous studies have shown that B. gauderio significantly modifies its EOD waveform in response to circadian and social cues via direct action of melanocortin peptide hormones on the electrocytes (Markham \& Stoddard 2005; Markham \& Stoddard 2013). Circadian plasticity of the EOD waveform has also been reported in B. occidentalis (Hagedorn 1995). Here we report similar ACTH-mediated EOD plasticity in three additional species of Brachyhypopomus (B. bennetti, B. brevirostris and B. cf. hamiltoni).

The extent of this EOD plasticity and its regulation varies by sex and ontogeny in $B$. gauderio (Markham \& Stoddard 2013). Though our sample size is insufficient to confirm demographic variation for the species tested here, it is interesting that the plasticity seems consistent throughout the genus (Fig.1) with B. bennetti as an exception. While some fishes from other gymnotiform genera exhibit ACTH-mediated EODa plasticity (McAnelly \& Zakon 1996; Markham et al 2009), others do not (Saenz, unpublished data). The function of this plasticity is not yet fully understood, but two probable roles are social and energetic. The active 
electrosensory system can be metabolically costly. Estimates of EOD production costs range from $4 \%$ to $22 \%$ of the daily metabolic budget in species with relatively slow EOD repetition rates such as B. gauderio (Salazar \& Stoddard 2008) and may cost well over $30 \%$ in species with higher repetition rates such as Eigenmannia virescens (Sternopygidae) (Lewis et al. 2014). Previous studies have reasonably argued that circadian regulation of EODa is adaptive for conserving energy. Therefore, it is interesting that B. bennetti shows decreased EODa plasticity, especially considering that its EODa is 3 to 8 times larger than those of sympatric congeners (Crampton \& Albert 2006) and the present results suggest that the physiology of EOD production is energetically inefficient in this species.

Another surprising finding was the magnitude of AP2 in B. bennetti electrocytes and the presence of voltage-gated $\mathrm{Na}^{+}$channels on the anterior membrane. The current clamp data suggest that, while the EOD of $B$. bennetti is monophasic, the $\mu \mathrm{EOD}$ is still composed of two APs. Because these APs completely overlap, the discharge from the anterior face (AP2) negates a significant fraction of AP1, potentially wasting considerable energy. Bennett (1971) recorded electrocytes from a monophasic Hypopomid, likely B. bennetti, but argued that the anterior membrane is electrically inexcitable. Instead, it was suggested that a smaller spike from the uninnervated membrane is a discharge of the membrane's capacitance, similar to what is suggested to occur in the uninnervated face of electrocytes in Gymnarchus niloticus, an African weakly electric fish (Bennett 1971; Schwartz et al. 1975). Our finding that voltage-gated $\mathrm{Na}^{+}$ channels are indeed present on the anterior face, in conjunction with our electrophysiology data and computational simulations, suggests the anterior membrane is, in fact, excitable.

The presence of $\mathrm{Na}^{+}$channels and generation of AP2 on the anterior membrane provides evidence against the long-standing assumption that B. bennetti's monophasic EOD is a retention of the pedomorphic monophasic condition. Is this electrical excitability of the anterior membrane a costly vestige of $B$. bennetti's biphasic ancestry or does AP2 serve some unknown function? While the sample sizes of the in vitro assays are admittedly small, it is nonetheless compelling that multiple lines of evidence from each assay point to the same conclusion: B. bennetti electrocytes have $\mathrm{Na}^{+}$channels on the anterior membrane that contribute to a second membrane depolarization of significant magnitude. Consequently, AP2 decreases the energetic efficiency of 
the EOD, without the benefit of producing a biphasic EOD to cloak the EOD from electroreceptive predators.

\section{The persistence of the monophasic EOD}

The biphasic EOD is likely an adaptation to predation pressures from eavesdropping electroreceptive predators (e.g. catfishes, electric eels, freshwater rays; Hanika \& Kramer 1999, 2000; Stoddard 1999). The two EOD phases sum at a short distance away from the fish, attenuating the low-frequency DC component of the EOD detectible by ampullary receptors of predators. Consequently, at greater distances DC-balanced EODs are theoretically not detectible by electroreceptive predators (Stoddard 1999; Stoddard \& Markham 2008; Stoddard et al. 2019). B. bennetti's monophasic EOD represents the asymmetrical extreme, with a large DC component and large amplitude augmenting its detectability by electroreceptive predators.

Previous studies have suggested that $B$. bennetti's EOD functions as a Batesian mimic of the Electric Eel's monophasic EOD (Stoddard 1999). This fish is the only gymnotiform capable of producing a strong electric discharge to incapacitate predators and prey alike. Crampton \& Albert (2006) argue that this mimicry is not a likely evolutionarily stable strategy due to a large discrepancy in the relative abundance of B. bennetti and E. electricus, the former being three orders of magnitude more abundant than the latter. Instead, Crampton \& Albert (2006) suggest the persistence of the monophasic EOD is related to species recognition.

Sensory bias and a female preference for signals with low frequency energy could further explain the reversion to a monophasic EOD. Sexual dimorphism has been documented in many gymnotiform species. According to Crampton \& Albert (2006), B. bennetti males produce EODs with amplitudes 2-3 times larger than females of comparable sizes, likely because they possess relatively larger sized electrocytes compared to juvenile and females (Crampton et al. 2016b). Building on the hypothesis of compatible mate ("species") recognition, it is possible that the monophasic EOD of $B$. bennetti could be a result of sexual selection. Consistent with handicap principle, female preference for a large amplitude could select for a costly signal both in terms of energetics and susceptibility to predation (Zahavi 1975). A mate choice study on B. gauderio suggests that EODa is the most salient EOD feature used by females to assess potential mates (Curtis and Stoddard 2003). Maximum EODa is largely a function of fish size, with larger individuals having more electrocytes thus producing larger EODs. Larger amplitudes also imply 
greater metabolic costs (larger APs require more ATP to restore electrocyte membrane potential per EOD), meaning a large amplitude could serve as an honest indicator of male condition. Still, mate choice studies with $B$. bennetti are needed to test this potential preference.

\section{Conclusion}

This and other recent studies (Ban et al. 2015) highlight that our understanding of electrocyte physiology is still very incomplete, especially with respect to the localization of different ion channel populations on the electrocyte membrane. Researchers have recognized the importance of the heterogenous distribution of ion channels in electrocytes since early studies in the Electric Eel (Ellisman \& Levinson 1982; Fritz et al. 1983), yet little is known about the regulatory mechanisms contributing to their localization. In many cases, the density and distribution of specific ion channels is critical for the function of nerve cells, such as in the nodes of Ranvier (Schulz et al. 2008) or the axon initial segment (AIS) (Kole et al. 2008), and abnormalities in channel localization can lead to neural pathologies (England et al. 1996). Further study of electrocyte ion channels in weakly electric fishes could improve our understanding of the processes governing ion channel localization as well as their evolutionary underpinnings.

In addition, these findings show the need for a better understanding of the ecology of these species and the adaptive significance of EOD plasticity. In view of B. bennetti's broad geographical distribution and abundance (Crampton et al. 2016b), it seems the energetic and predation handicaps considered here have not hindered its ecological success and point to other unknown aspects of its ecology, such as mate choice preferences and levels of intraspecific competition (Gavassa et al. 2012a, b). Natural history studies of these animals are sorely missing, and sadly, we could be running out of time. Due to the metabolic demands of their unique sensory systems, weakly electric fishes may be disproportionately susceptible to environmental disturbances such as those induced by climate change and the rapid changes in land use currently occurring in the Amazon (Markham et al. 2016; Montag et al. 2019). 


\section{References}

Albert, J.S. and Crampton, W.G. (2005). Diversity and phylogeny of Neotropical electric fishes (Gymnotiformes). In Electroreception, pp. 360-409. Springer, New York, NY.

Alda, F., Tagliacollo, V.A., Bernt, M.J., Waltz, B.T., Ludt, W.B., Faircloth, B.C., Alfaro, M.E., Albert, J.S. and Chakrabarty, P. (2018). Resolving Deep Nodes in an Ancient Radiation of Neotropical Fishes in the Presence of Conflicting Signals from Incomplete Lineage Sorting. Syst. Biol. 68(4), 573-593.

Allee, S. J., Markham, M. R., \& Stoddard, P. K. (2009). Androgens enhance plasticity of an electric communication signal in female knifefish, Brachyhypopomus pinnicaudatus. Horm. Behav. 56(2). 264-273.

Arnegard, M.E., McIntyre, P.B., Harmon, L.J., Zelditch, M.L., Crampton, W.G., Davis, J.K., Sullivan, J.P., Lavoué, S. and Hopkins, C.D. (2010). Sexual signal evolution outpaces ecological divergence during electric fish species radiation. Am. Nat. 176(3), 335-356.

Bennett MLV. (1961). Modes of operation of electric organs. Ann. N. Y. Acad. Sci. 94(2). 458509.

Bennett MLV. (1971). Electric organs. In: WS Hoar, DJ Randal (eds). Fish Physiology, (Vol 5. pp 347-491). Academic Press, New York.

Crampton, W. G. R. \& J. S. Albert. (2006). Evolution of electric signal diversity in gymnotiform fishes. I. Phylogenetic systematics, ecology and biogeography. 647-696; 718-731. In: Ladich F., S. P. Collin, P. Moller \& B. G. Kapoor (Eds.). Communication in fishes. Enfield, NH, Science Publishers.

Crampton, W.G.R., de Santana, C.D., Waddell, J.C. and Lovejoy, N.R. (2016a). Phylogenetic systematics, biogeography, and ecology of the electric fish genus Brachyhypopomus (Ostariophysi: Gymnotiformes). PloS One. 11(10), p.e0161680.

Crampton, W.G., Santana, C.D.D., Waddell, J.C. and Lovejoy, N.R. (2016b). A taxonomic revision of the Neotropical electric fish genus Brachyhypopomus (Ostariophysi: Gymnotiformes: Hypopomidae), with descriptions of 15 new species. Neotrop. Ichthyol. 14(4). e150146.

Curtis, C.C. and Stoddard, P.K. (2003). Mate preference in female electric fish, Brachyhypopomus pinnicaudatus. Anim. Behav. 66(2), 329-336.

Ellisman, M.H. and Levinson, S.R. (1982). Immunocytochemical localization of sodium channel distributions in the excitable membranes of Electrophorus electricus. Proc. Natl. Acad. Sci. U.S.A. 79(21), 6707-6711.

England, J.D., Happel, L.T., Kline, D.G., Gamboni, F., Thouron, C.L., Liu, Z.P. and Levinson, S.R. (1996). Sodium channel accumulation in humans with painful neuromas. Neurology. 47(1), 272-276.

Ferrari, M.B., McAnelly, M.L. and Zakon, H.H. (1995). Individual variation in and androgen modulation of the sodium current in electric organ. J. Neurosci. 15(5), 4023-4032.

Franchina, C. R. (1997). Ontogeny of the electric organ discharge and the electric organ in the weakly electric pulse fish Brachyhypopomus pinnicaudatus (Hypopomidae, Gymnotiformes). J. Comp. Physiol. A. 181(2), 111-119. 
Fritz, L.C., Moore, H.P., Raftery, M.A. and Brockes, J.P. (1983). Immunochemical Studies of the Voltage-sensitive Sodium Channel from the Electroplax of the Eel Electrophorus electricus. In Cold Spring Harbor symposia on quantitative biology, 48, 181-185. Cold Spring Harbor Laboratory Press.

Gavassa, S., Silva, A.C., Gonzalez, E. and Stoddard, P.K. (2012a). Signal modulation as a mechanism for handicap disposal. Anim. Behav. 83(4), 935-944.

Gavassa, S., Silva, A.C., Gonzalez, E., Molina, J. and Stoddard, P.K. (2012b). Social competition masculinizes the communication signals of female electric fish. Behav. Ecol. Sociobiol. 66(7), 1057-1066.

Hagedorn, M. (1995). The electric fish Hypopomus occidentalis can rapidly modulate the amplitude and duration of its electric organ discharges. Anim. Behav. 49(5), 1409-1413.

Hanika, S. and Kramer, B. (1999). Electric organ discharges of mormyrid fish as a possible cue for predatory catfish. Naturwissenschaften. 86(6), 286-288.

Hanika, S. and Kramer, B. (2000). Electrosensory prey detection in the African sharptooth catfish, Clarias gariepinus (Clariidae), of a weakly electric mormyrid fish, the bulldog (Marcusenius macrolepidotus). Behav. Ecol. Sociobiol. 48(3), 218-228.

Kole, M.H., Ilschner, S.U., Kampa, B.M., Williams, S.R., Ruben, P.C. and Stuart, G.J. (2008). Action potential generation requires a high sodium channel density in the axon initial segment. Nat. Neurosci. 11(2), p.178.

Lewis, J.E., Gilmour, K.M., Moorhead, M.J., Perry, S.F. and Markham, M.R. (2014). Action potential energetics at the organismal level reveal a trade-off in efficiency at high firing rates. J. Neurosci. 34(1), 197-201.

Lovejoy, N. R., Lester, K., Crampton, W. G. R., Marques, F. P. L. and Albert, J. S. (2010). Phylogeny, biogeography, and electric signal evolution of neotropical knifefishes of the genus Gymnotus (Osteichthyes: Gymnotidae). Mol. Phylogenet. Evol. 54(1), 278-290.

Markham, M.R. \& Stoddard, P.K. (2005). Adrenocorticotropic hormone enhances the masculinity of an electric communication signal by modulating the waveform and timing of action potentials within individual cells. J. Neurosci. 25(38), 8746-8754.

Markham, M.R., McAnelly, M.L., Stoddard, P.K. and Zakon, H.H. (2009). Circadian and social cues regulate ion channel trafficking. PLoS Biol. 7(9), p.e1000203.

Markham, M. R. (2013). Electrocyte physiology: 50 years later. J. Exp. Biol. 216(13), 24512458.

Markham, M. R., \& Stoddard, P. K. (2013). Cellular mechanisms of developmental and sex differences in the rapid hormonal modulation of a social communication signal. Horm. Behav. 63(4), 586-597.

Markham, M.R., Kaczmarek, L.K. and Zakon, H.H. (2013). A sodium-activated potassium channel supports high-frequency firing and reduces energetic costs during rapid modulations of action potential amplitude. J. Neurophysiol. 109(7), 1713-1723.

Markham, M. R., \& Zakon, H. H. (2014). Ionic mechanisms of microsecond-scale spike timing in single cells. J. Neurosci. 34(19), 6668-6678.

Markham, M.R., Ban, Y., McCauley, A.G. and Maltby, R. (2016). Energetics of sensing and communication in electric fish: A blessing and a curse in the Anthropocene?. Integr. Comp. Biol. 56(5), 889-900. 
McAnelly, L. \& Zakon, H.H. (1996). Protein kinase A activation increases sodium current magnitude in the electric organ of Sternopygus. J. Neurosci. 16(14), 4383-4388.

Montag, L.F., Winemiller, K.O., Keppeler, F.W., Leão, H., Benone, N.L., Torres, N.R., Prudente, B.S., Begot, T.O., Bower, L.M., Saenz, D.E., et al. (2019). Land cover, riparian zones and instream habitat influence stream fish assemblages in the eastern Amazon. Eco. Freshw. Fish. 28(2), 317-329.

Salazar, V.L. and Stoddard, P.K., (2008). Sex differences in energetic costs explain sexual dimorphism in the circadian rhythm modulation of the electrocommunication signal of the gymnotiform fish Brachyhypopomus pinnicaudatus. Journal of Experimental Biology, 211(6), 1012-1020.

Schulz, D.J., Temporal, S., Barry, D.M. and Garcia, M.L. (2008). Mechanisms of voltage gated ion channel regulation: from gene expression to localization. Cell. Mol. Life Sci. 65(14), 2215-2231.

Schwartz, I.R., Pappas, G.D. and Bennett, M.V. (1975). The fine structure of electrocytes in weakly electric teleosts. J. Neurocytol. 4(1), 87-114.

Silva, A., Quintana, L., Ardanaz, J.L. and Macadar, O. (2002). Environmental and hormonal influences upon EOD waveform in gymnotiform pulse fish. J. Physiol. Paris. 96(5-6), 473-484.

Silva, A., Perrone, R., \& Macadar, O. (2007). Environmental, seasonal, and social modulations of basal activity in a weakly electric fish. Physiol. Behav. 90(2-3), 525-536.

Stoddard, P.K. (1999). Predation enhances complexity in the evolution of electric fish signals. Nature. 400(6741), p.254.

Stoddard, P. K. (2002). The evolutionary origins of electric signal complexity. J. Physiol. Paris. 96(5-6), 485-491.

Stoddard PK, Markham MR, Salazar VL. (2003). Serotonin modulates the electric waveform of the gymnotiform electric fish Brachyhypopomus pinnicaudatus. J. Exp. Biol. 206(8), 1353-1362.

Stoddard, P.K. \& Markham, M.R. (2008). Signal cloaking by electric fish. Bioscience. 58(5), 415-425.

Stoddard, P.K., Tran, A. and Krahe, R. (2019). Predation and crypsis in the evolution of electric signaling in weakly electric fishes. Front. Ecol. Evol. 7, p.264.

Sullivan, J.P., Zuanon, J. and Fernandes, C.C. (2013). Two new species and a new subgenus of toothed Brachyhypopomus electric knifefishes (Gymnotiformes, Hypopomidae) from the central Amazon and considerations pertaining to the evolution of a monophasic electric organ discharge. ZooKeys. (327), p.1.

Tagliacollo, V. A., Bernt, M. J., Craig, J. M., Oliveira, C., \& Albert, J. S. (2016). Model based total evidence phylogeny of Neotropical electric knifefishes (Teleostei, Gymnotiformes). Mol. Phylogenet Evol. 95, 20-33.

Trujillo-Cenóz, O., Echagüe, J.A. and Macadar, O. (1984). Innervation pattern and electric organ discharge waveform in Gymnotus carapo (Teleostei; Gymnotiformes). $J$. Neurobiol. 15(4), 273-281.

Waddell, J.C., Njeru, S.M., Akhiyat, Y.M., Schachner, B.I., Correa-Roldán, E.V. and Crampton, W.G. (2019). Reproductive life-history strategies in a species-rich assemblage of Amazonian electric fishes. PloS One. 14(12), p.e0226095.

Zahavi, A. (1975). Mate selection—a selection for a handicap. J. Theor. Biol. 53(1), 205-214. 
Derived loss of signal complexity 20

Table 1. Parameter values for the electrocyte model.

\begin{tabular}{|c|c|c|}
\hline Parameter & $\begin{array}{c}\text { Anterior } \\
\text { Compartment }\end{array}$ & $\begin{array}{c}\text { Posterior } \\
\text { Compartment }\end{array}$ \\
\hline $\bar{g}_{N a}$ & $150 \mu \mathrm{S}$ & $400 \mu \mathrm{S}$ \\
\hline$V 50_{m}$ & $-37.73 \mathrm{mV}$ \\
\hline$k_{m}$ & 9.02 \\
\hline$V 50_{h}$ & $-57.52 \mathrm{mV}$ \\
\hline$k_{h}$ & -9.625 \\
\hline$\alpha_{m}$ & $0.3096 \mathrm{~ms}$ \\
\hline$\mu_{m}$ & $-55.0 \mathrm{mV}$ \\
\hline$\sigma_{m}$ & $11.991 \mathrm{mV}$ \\
\hline$\beta_{m}$ & $0.1057 \mathrm{~ms}$ \\
\hline$\alpha_{h}$ & $2.50 \mathrm{~ms}$ \\
\hline$\mu_{h}$ & $-50.0 \mathrm{mV}$ \\
\hline$\sigma_{h}$ & $5.373 \mathrm{mV}$ \\
\hline$\beta_{h}$ & $0.3121 \mathrm{~ms}$ \\
\hline $\bar{g}_{L}$ & $50 \mu \mathrm{S}$ \\
\hline & \\
\hline & \\
\hline
\end{tabular}


Figure 1. Current phylogeny of Brachyhypopomus adapted with permission from Crampton et al. (2016b). Species in red boxes are known to display circadian changes in EOD waveform. $B$. occidentalis was recorded by Hagedorn (1995). Insets at right show the EOD waveforms of the biphasic species $B$. gauderio and monophasic B. bennetti. Red dashed lines show nightly waveform changes. Inset at upper left shows the same EOD waveforms, with amplitudes scaled to the same baseline amplitude. The baseline EOD amplitude is larger in B. bennetti; however, the magnitude of the EOD amplitude change is much smaller.

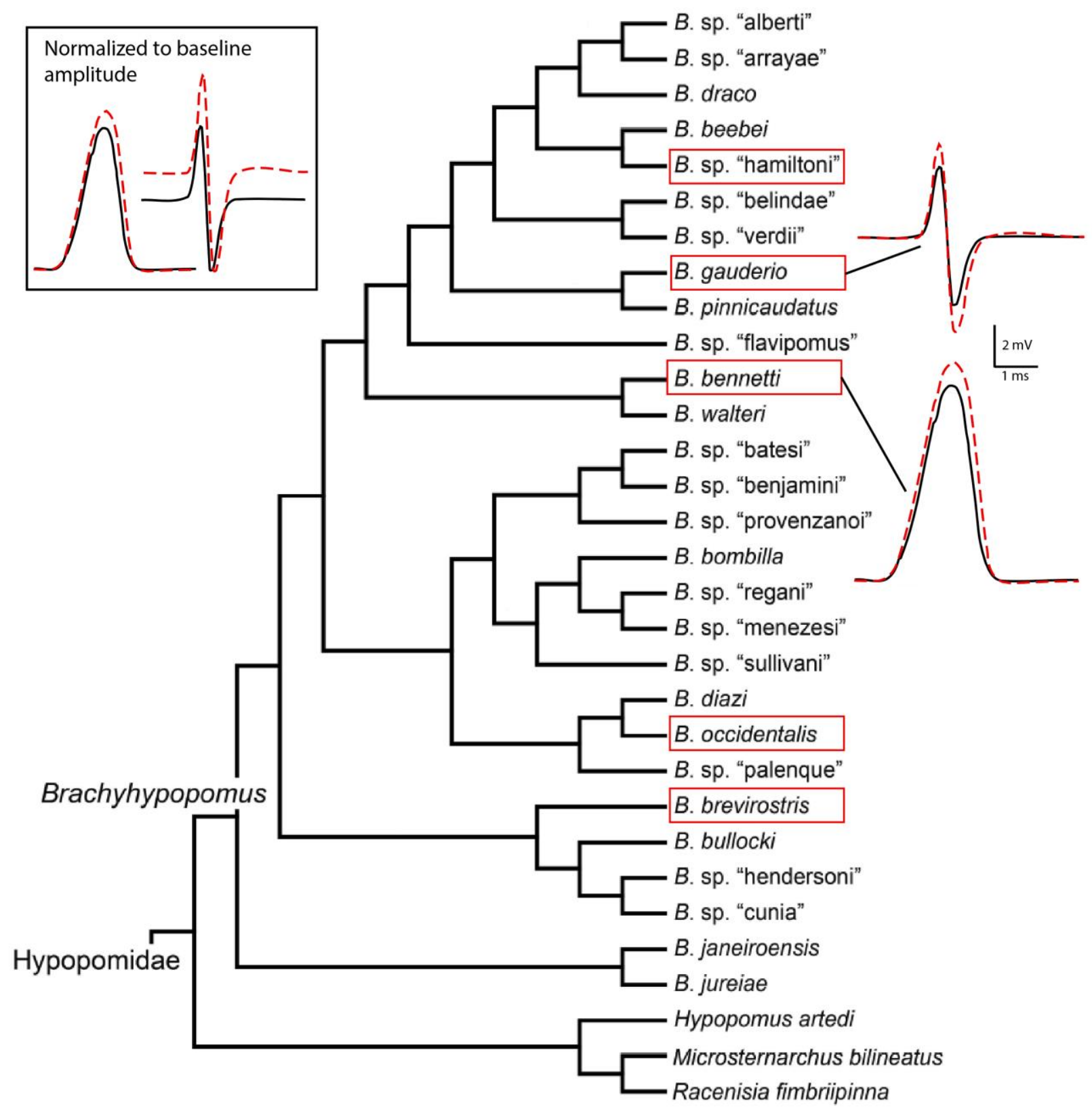


bioRxiv preprint doi: https://doi.org/10.1101/2021.02.06.430027; this version posted February 8, 2021. The copyright holder for this preprint

(which was not certified by peer review) is the author/funder. All rights reserved. No reuse allowed without permission.

Derived loss of signal complexity 22

Figure 2. Immunolabeling of axon terminal and voltage-gated $\mathrm{Na}^{+}$channels in electrocytes of the monophasic B. bennetti. The center column shows the full cell. Dashed boxes show delineate enhanced images of the anterior membrane shown on the left column and the posterior membrane shown on the right. (A-C) DAPI labels the electrocyte nuclei and provides a relative outline of electrocytes. (D-F) Anti-Pan $\mathrm{NaV}$ labels $\mathrm{Na}^{+}$channels. Punctuated dots are visible on both membranes as well as on internal structures. (G-I) 3A10 labels the axon terminal on the stalk. (J-L) Merged images of the three previous rows. Scale bar: $100 \mu \mathrm{m}$
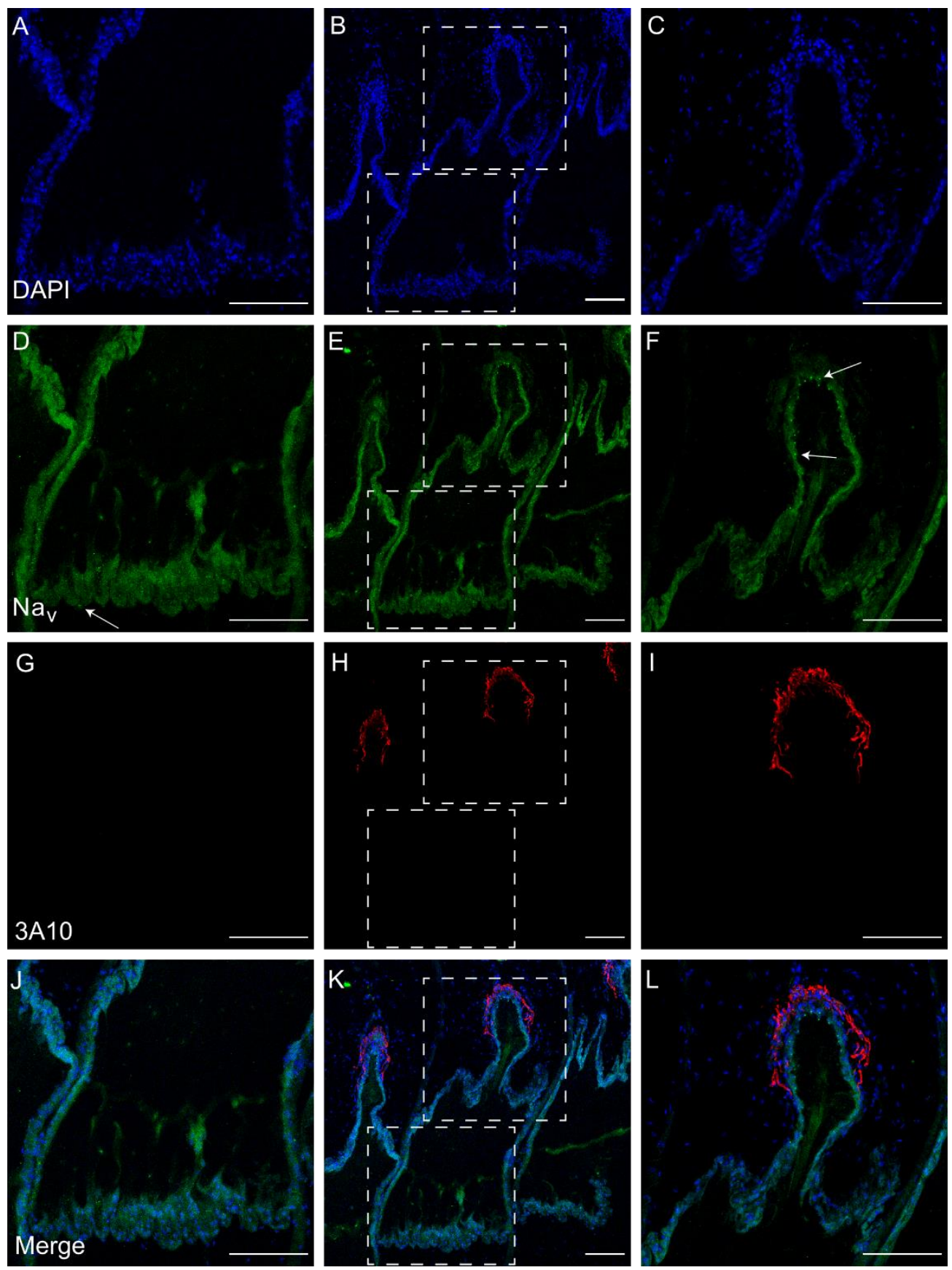
bioRxiv preprint doi: https://doi.org/10.1101/2021.02.06.430027; this version posted February 8, 2021. The copyright holder for this preprint (which was not certified by peer review) is the author/funder. All rights reserved. No reuse allowed without permission.

Derived loss of signal complexity 23

Figure 3. Immunolabeling of axon terminal and voltage-gated $\mathrm{Na}^{+}$channels in the electrocytes of the biphasic species B. gauderio. A) DAPI labeling of nuclei provides the general outline of the electrocyte. B) Anti-Pan $\mathrm{NaV}$ labels $\mathrm{Na}^{+}$channels. The central arrow highlights puncta present on internal structures. C) A \& B merged. D) DAPI labels the nuclei outlining the stalk of a different cell. E) 3A10 labels the axon terminal on the stalk. F) D \& E merged. Scale bar: 100 $\mu \mathrm{m}$
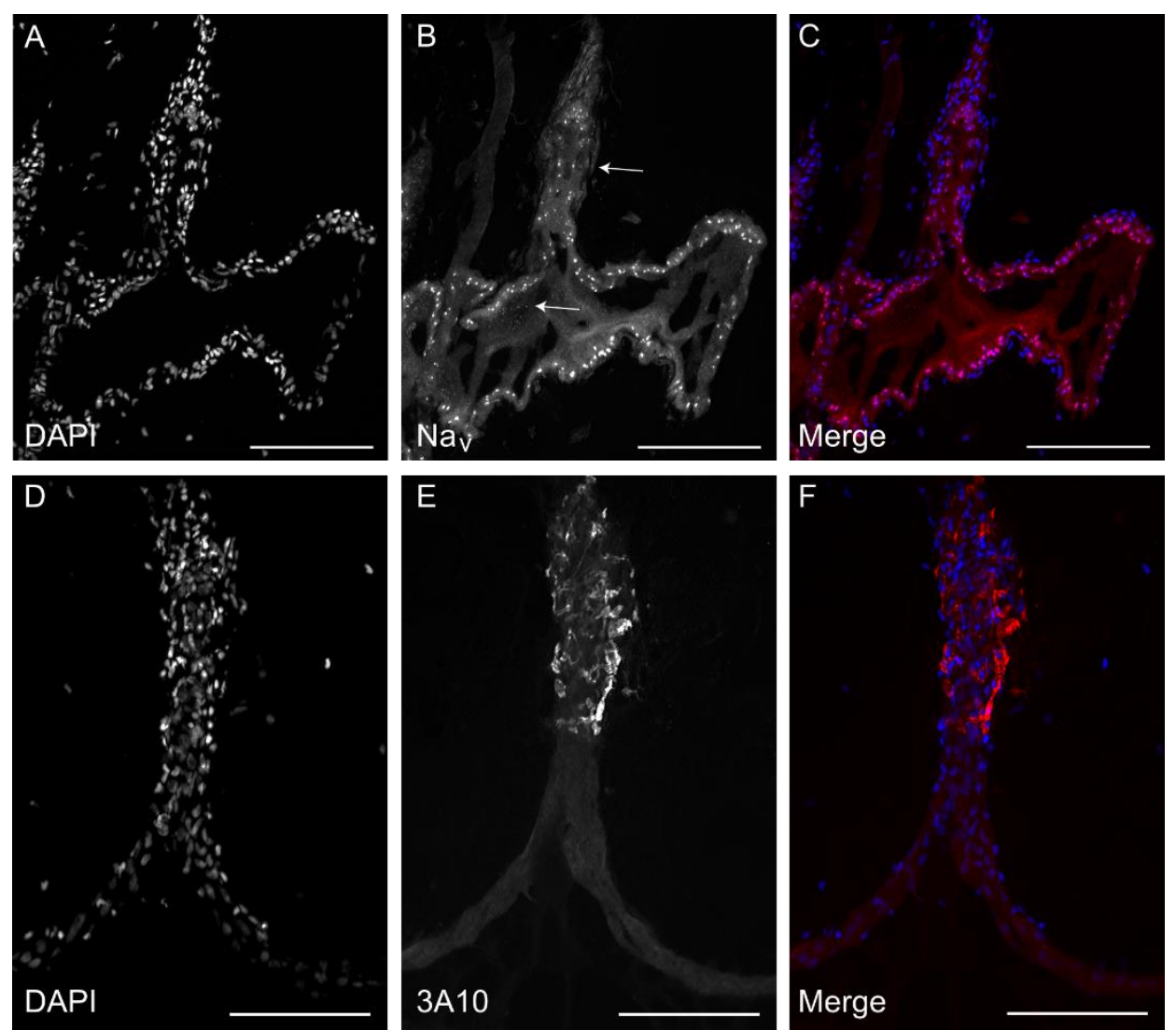
bioRxiv preprint doi: https://doi.org/10.1101/2021.02.06.430027; this version posted February 8, 2021. The copyright holder for this preprint

(which was not certified by peer review) is the author/funder. All rights reserved. No reuse allowed without permission.

Derived loss of signal complexity 24

Figure 4. $\mathrm{Na}^{+}$channels were present in both anterior (up) and posterior (down) membranes of the electrocytes in the monophasic species B. bennetti. (A and D) DAPI labels the electrocyte nuclei and provides a relative outline of electrocytes with the caudal stalk prominently visible. Control cells with only the secondary antibody (Alexa Fluor 488; B and C) show minimal autofluorescence but no positive signals indicating the specific signals ( $\mathrm{E}$ and $\mathrm{F}$ ) come from primary antibody (Anti-Pan Nav) and the presence of voltage-gated $\mathrm{Na}^{+}$channels in the electrocyte membrane. High magnification image revealed the punctuated dot signals (arrows) located on the anterior membrane, contrary to our expectations (F). Punctuated dots are also visible on internal structures of electrocytes (F) Scale bar: $100 \mu \mathrm{m}$
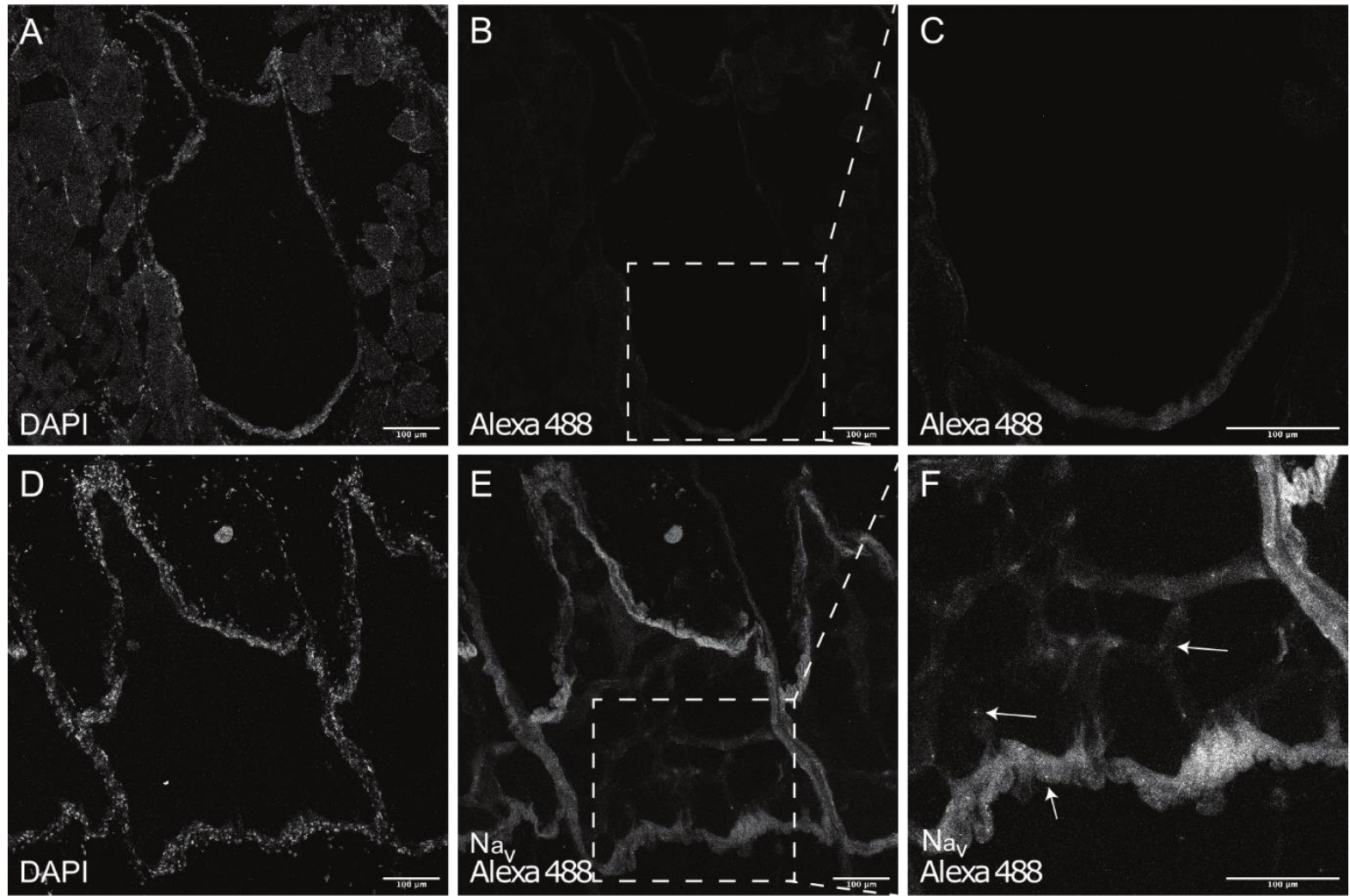
Figure 5. Electrocyte action potentials and response to ACTH in B. bennetti and $B$. brevirostris electrocytes. A, Representative recordings from a $B$. bennetti electrocyte of AP1 (red) and AP2 (blue) with the resulting $\mu \mathrm{EOD}$ (black). Dashed lines show the action potentials and $\mu$ EOD 30 minutes after perfusion of ACTH. B, Recordings showing percent change in $\mu \mathrm{EOD}$ amplitude for 5 different $B$. bennetti individuals, after perfusion of either a saline control (1) or ACTH (4). C, Recordings from a B. brevirostris electrocyte of AP1 (red) and AP2 (blue) with the resulting $\mu \mathrm{EOD}$ (black). Dashed lines show the action potentials and $\mu \mathrm{EOD} 30$ minutes after perfusion of ACTH. D, Percent change in $\mu$ EOD amplitude for one B. brevirostris electrocyte in response to $\mathrm{ACTH}$.

A

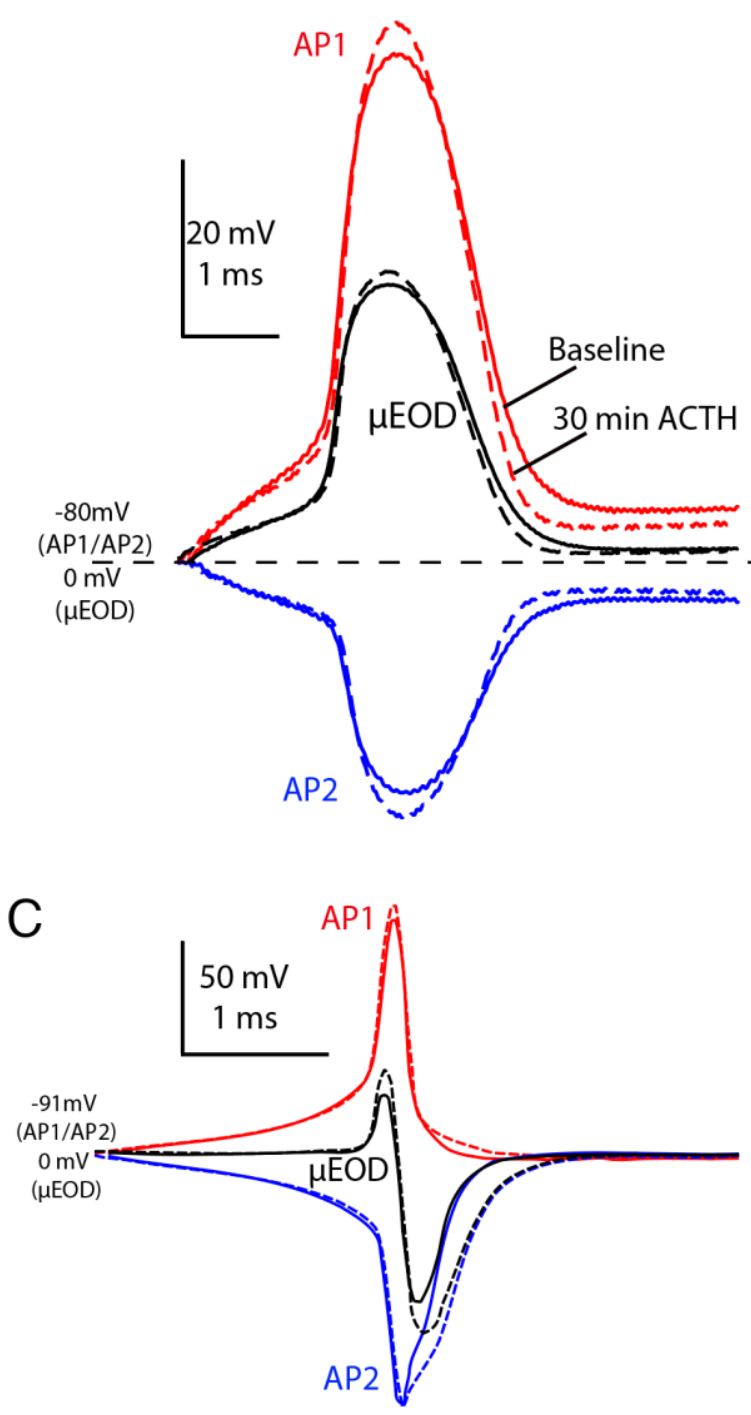

B

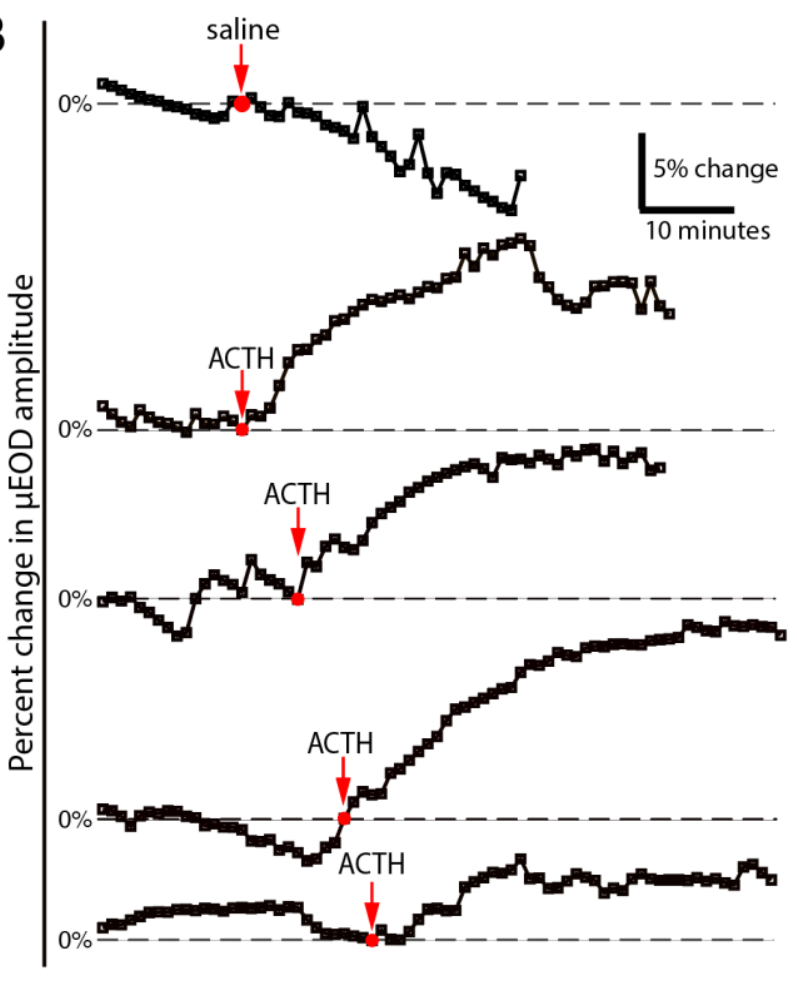

$\mathrm{D}$

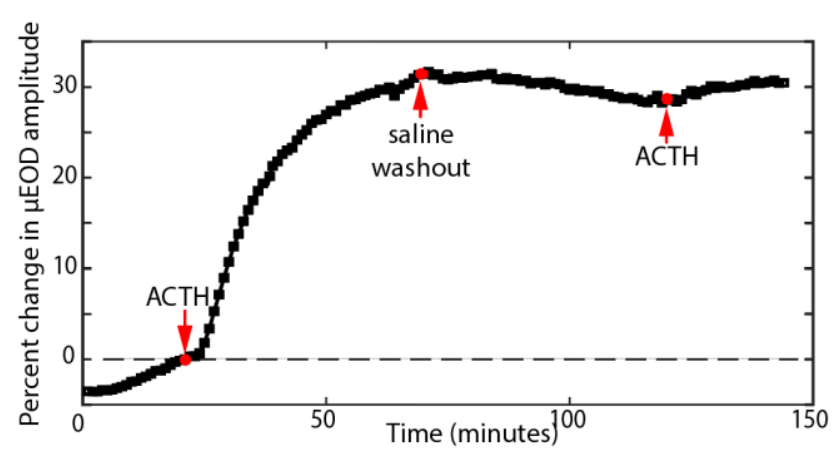


Figure 6. Characterization of $\boldsymbol{B}$. bennetti $\mathrm{Na}^{+}$currents. A) Whole-cell I-V relationships at steady state in $B$. bennetti electrocytes are linear and show no evidence of significant inward- or outward-rectifying $\mathrm{K}^{+}$currents. In all panels symbols are means and error bars represent SEM. B) Representative currents elicited by voltage steps from -115 to $20 \mathrm{mV}$ in $5 \mathrm{mV}$ increments. Inset is voltage command protocol, which was also used for data shown in C and D. C) Activation and inactivation $\mathrm{GV}$ plots for $\mathrm{Na}^{+}$currents. Solid lines are Boltzmann sigmoidal fits.

D) Activation and inactivation $\tau$-V curves. Solid line is a Gaussian fit for inactivation data and a Lorentzian fit for activation data. E) $\mathrm{I}_{\mathrm{Na}}$ recovery from inactivation. Solid line represents a single-exponential fit. Inset is the voltage command protocol.
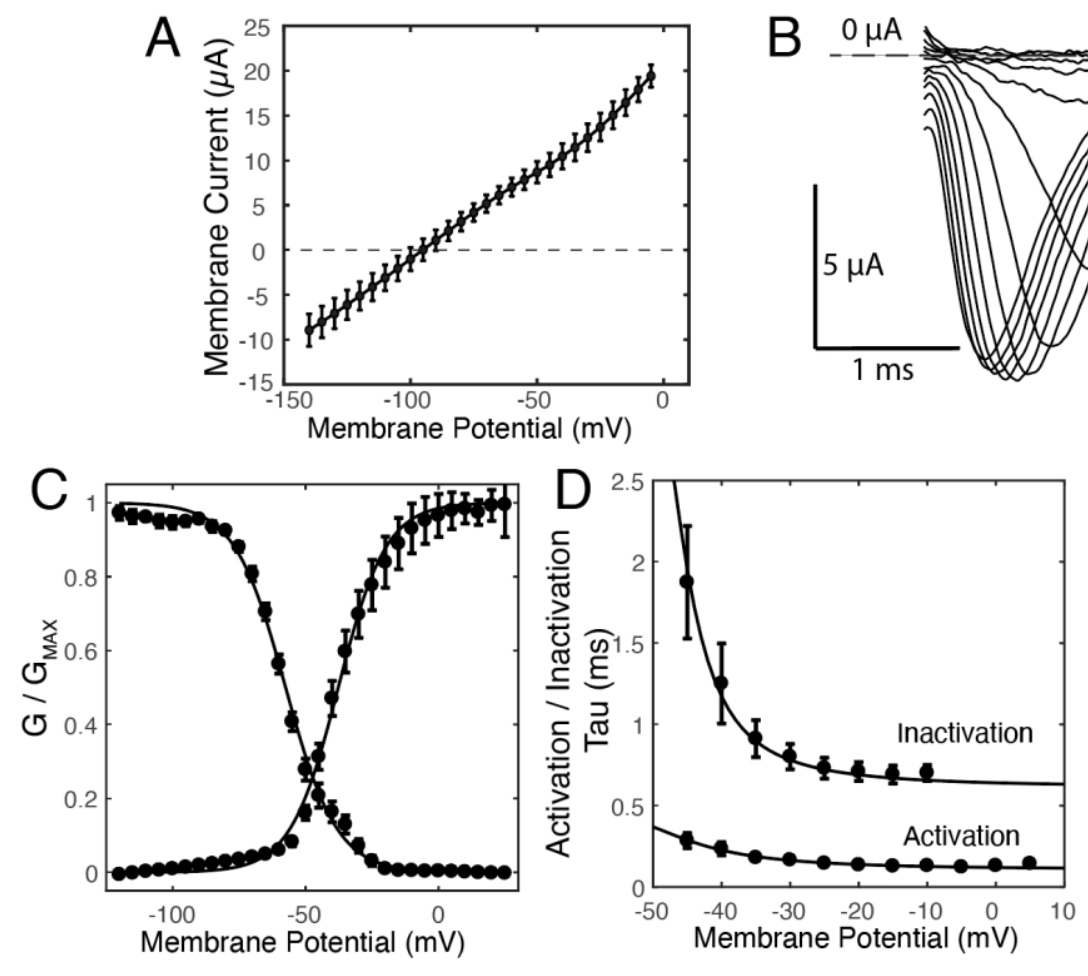
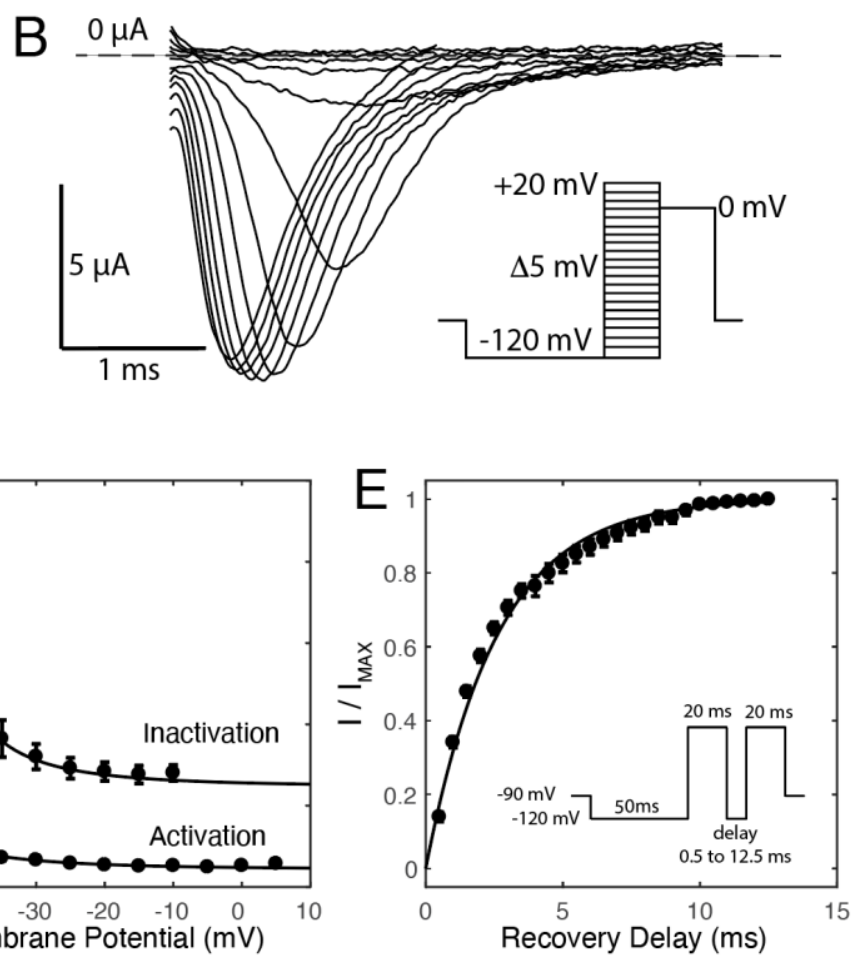
Figure 7. Computational simulations of B. bennetti electrocytes. Simulation of action potentials based on experimental measurements of $\mathrm{Na}^{+}$conductance parameters under voltage clamp. Stimulation is a 3-ms step current of 4,400 nA (not shown). Passive membrane responses to stimulus current are not shown. Red lines represent the posterior compartment, blue lines represent the anterior compartment, and black lines represent whole-cell $\mu$ EODs. Solid lines represent baseline simulations and dashed lines show simulations after $\mathrm{Na}^{+}$conductances are increased by $10 \%$ in both the anterior and posterior compartments. Scale bars apply to all figure panels. A) Responses of baseline model electrocyte with all parameters as in Table 1. Action potentials closely resemble those recorded experimentally (compare to Fig. 5A). B) Responses of a model electrocyte where the anterior $\mathrm{Na}^{+}$conductance is eliminated. C) Responses of a model electrocyte where the anterior $\mathrm{Na}^{+}$conductance is eliminated and the anterior compartment capacitance is increased by a factor of 10 to a value of $500 \mathrm{nF}$.
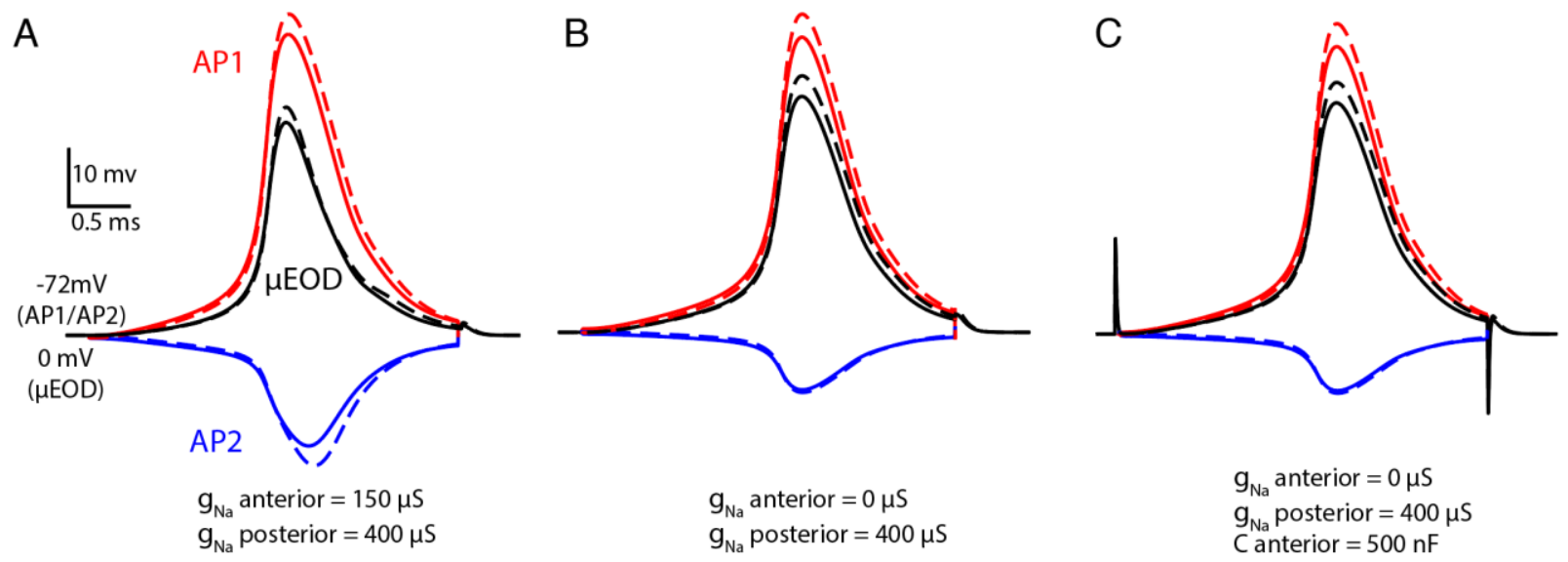
bioRxiv preprint doi: https://doi.org/10.1101/2021.02.06.430027; this version posted February 8, 2021. The copyright holder for this preprint (which was not certified by peer review) is the author/funder. All rights reserved. No reuse allowed without permission.

Derived loss of signal complexity 28

Acknowledgements - We would like to thank Jose Alves Gomes for lab space and assistance in the field, Tiago Pires and Jansen Zuanon for enabling fish transport, Rosemary Knapp for cryotome use and assistance, JP Masly for use of his Zeiss microscope, and Rosalie Maltby for fish care. 